\title{
Preface: Proceedings of the XXI. International Scientific Conference - The Application of Experimental and Numerical Methods in Fluid Mechanics and Energy 2018
}

\author{
(XXI. AEaNMiFMaE-2018)
}

The International Scientific Conference on Application of Experimental and Numerical Methods in Fluid Mechanics and Energy 2018 (XXI. AEaNMiFMaE-2018) has been scheduled to take place at Hotel DIPLOMAT - Rajecké Teplice, Slovakia, between 25-27 April 2018.

The aim of the international conference is to bring together researchers, designers, experimenters, modeller's and numerical analysts from laboratories, industry and academia working in the field of twophase and multiphase flow and experimental methods used in the field of fluid mechanics, thermodynamics and energy.

The international conference covers all topics in Measurement and calculation of state variables in the fluid flow, modelling and simulation in fluid mechanics and energy, optimization of flow parameters in thermal and hydraulic machines and systems, the application of the latest knowledge in the field of fluid mechanics and energy in technical practice, flow visualization, measurement of the energy systems and systems, special experimental methods in fluid mechanics and energy, renewable energy, current problems in the energy sector.

The conference should contribute to the establishment closer contacts, presentations on the latest knowledge, exchange of experience in the application of different experimental methods, preparation and implementation experiments, results processing and numerical simulations of experiments.

The scientific committee determined the following conference topics:

- Measurement and calculation of state variables in the fluid flow.

- Modelling and simulation in fluid mechanics and energy.

- Optimization of flow parameters in the thermal and hydraulic machines and systems.

- Application of latest developments in the field of fluid mechanics and energy in technical practice.

- Visualization of flow.

- Measurement of energy systems and systems.

- Special experimental methods in fluid mechanics and energy.

- Renewable energy.

- Current problems in the energy.

\section{We would like thanks:}

- The Scientific Committee and Reviewers of AEaNMiFMaE-2018 for their help and support.

- The Session Chairman's for their considerable effort the managing of individual sections.

- The Guarantors of the conference (prof. Ing. Jozef Jandačka, PhD., Vice-Rector for Development, University of Zilina, Slovakia, prof. RNDr. Milan Malcho, PhD., University of Zilina, Slovakia). 